\title{
Use of Senior Center and the Health-Related Quality of Life in Korean Older Adults
}

\author{
Hyun-Shik Kim ${ }^{1}$, Kazuhiro Harada ${ }^{2,3}$, Masashi Miyashita², Eun-A Lee ${ }^{2}$, Jin-Kee Park ${ }^{4}$, Yoshio Nakamura² \\ ${ }^{1}$ Graduate School of Sport Sciences, Waseda University, Tokorozawa, Japan; ${ }^{2}$ Faculty of Sport Sciences, Waseda University, Tokorozawa, \\ Japan; Japan Society for the Promotion of Science, Tokyo, Japan; ${ }^{4}$ College of Sport Science, Dong-A University, Busan, Korea
}

\begin{abstract}
Objective: The purpose of the present study was to examine the relationship between the use of senior center and health-related quality of life in Korean older adults.

Methods: A questionnaire survey was conducted to two types of older adults who lived in Busan, Korea: 154 older adults who used a senior center and 137 older adults who did not use a senior center. The Korean version of short-form 36-item health survey was administered to assess the health-related quality of life. Demographic variables were obtained from a questionnaire. These were gender, age, family status, marital status, education, monthly income, present illness, body mass index and physical activity.

Results: The 8-domain scales of physical function and role-physical were significantly higher in the users of the senior center compared with the non-users $(F=4.87, p=0.027$ and $F=7.02, p=0.009$, respectively). The 8-domain scales of vitality was also significantly higher in the users of the senior center compared with the non-users $(F=7.48$, $\mathrm{p}=0.007$ ).

Conclusions: The present study showed that the users of the senior center have higher physical function, role-physical and vitality compared with the non-users. These findings suggest that although the results are unable to specify causal relationships using the senior center may lead to some improvement in health-related quality of life.
\end{abstract}

Key words: Health-related quality of life, Long-term care prevention, Older adults, Senior center J Prev Med Public Health 2011;44(4):149-156

\section{INTRODUCTION}

Improving the quality of life is often the major goal in the provision of health care [1] and clinicians and policymakers recognize the importance of measuring healthrelated quality of life (HRQOL) in informing patient management, policy decisions [2] and resource allocation [3]. Recently, there is necessity for the evaluation of HRQOL to replenish the conventional evaluation methods that use different disease profile, with the death rate emphasized [4]. HRQOL is related to the measurement of the physical functional and basic health evaluation to understand people's state of health, including acknowledgment of feelings and social health understanding $[5,6]$.

Korea, like many developed countries with growing elderly populations, uses its senior centers as means of long-term health care and prevention. This policy came about in July 2008, when Korea implemented one of its most important health improvement services [7], the long-term care insurance system. This system was

(10) This is an Open Access article distributed under the terms of the Creative Common Attribution Non-Commercial License (http://creativecommons.org/licenses/by-nc/3.0/) which permits unrestricted non-commercial use, distribution, and reproduction in any medium, provided the original work is properly cited. developed primarily to promote the long-term health of the elderly through prevention [8]. It was thought that prevention would lead to a reduction in national medical expenditures and the stabilization of fiscal insurance costs [9], while concomitantly improving the overall health and quality of life (QOL) of senior citizens. As part of the implementation of the system, it was recommended that spending go not to large-scale infrastructure projects, but instead to existing senior centers.

Senior centers in Korea offer its senior citizens a wide variety of leisure and social activities, as well as programs and services that promote health and prevent disease. The centers are widely known in the community. As many as $83.7 \%$ of the senior citizens are at least aware of the senior centers, and $38.3 \%$ of them wish to use the facilities. Figure 1 shows a typical activity program offered by a senior center. Previous research has shown that participation in senior center activities influences the mental and physical health of the seniors involved $[10,11]$. The planning and construction of senior centers should take this into account.

Corresponding author: Yoshio Nakamura, PhD

2-579-15 Mikajima, Tokorozawa, Saitama, 359-1192, Japan

Tel : +81-4-2947-6829, Fax: +81-4-2947-6829, E-mail : nakamura@waseda.jp

Received : 27 October 2010, Accepted : 22 March 2011 


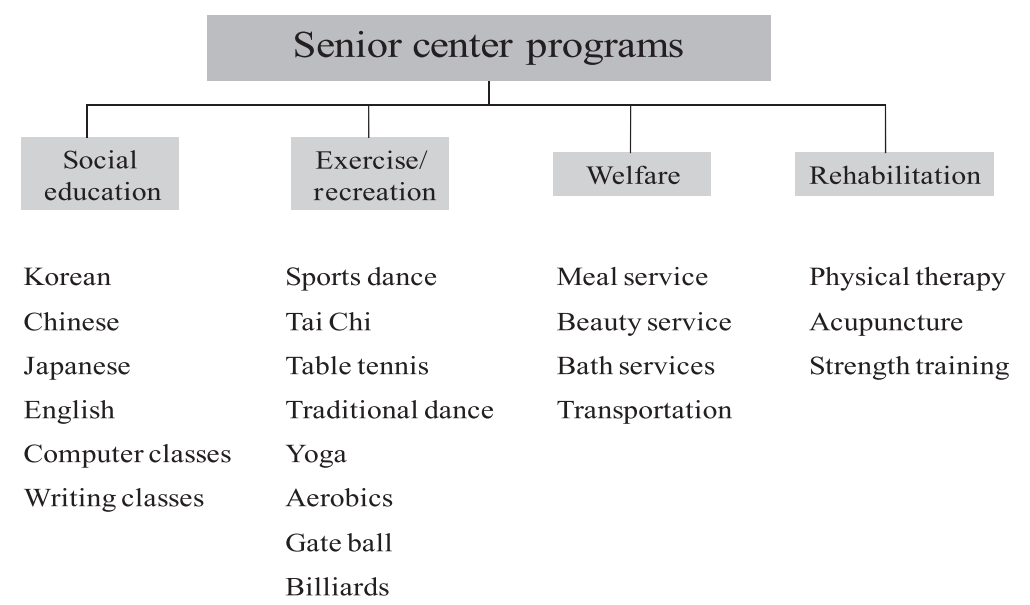

Figure 1. Typical activity programs offered by the senior canter.

Integrated health services and promotion are critical to long-term care and prevention [12]. Also a solid understanding of the HRQOL of senior citizens using the centers will help clarify how to effectively enhance them.

Conventional measures of HRQOL are often based on different disease profiles and mortality rates [4]. These purely physical measures, however, are in need of revaluation. A more holistic approach, one that includes measures of mental health aspects as well, is key to a proper understanding of HRQOL. Today's aging population has plenty of leisure time but little actual income. Socially and mentally, they often feel isolated and emotionally estranged. These feelings clearly have an impact on their QOL, and therefore should be included, along with physical health, in any study claiming to accurately measure the HRQOL of senior citizens. Previous research on senior centers have focused primarily on the relationship between physical health and factors like frequency and duration of attendance, user participation, which activities or services were utilized [13-17]; and while they did report improvements in chronic disease and physical function, they failed to examine actual HRQOL. The purpose of the study was to examine the relationship between the use of senior centers and the HRQOL in Korean older adults.

\section{METHODS}

\section{Samples}

\section{A. Participants}

This study used a two-group cross-sectional comparative design. Questionnaires were used to distinguish the characteristics of two groups living in Busan, Korea. The first group is those senior citizens who utilize a local senior center at least once a week [13] the "users" and the second group is those senior citizens who do not utilize a local senior center the "non-users." A random sample of users was chosen from among four of Busan's twelve senior centers. This group consisted of 154 respondents, $19.3 \%$ of whom were male, $80.7 \%$ of whom were female, aged $71.2 \pm 3.7$ years, mean \pm standard deviation (SD). The random sample of nonusers came from data culled by a research company. This group consisted of 137 respondents, aged $70.2 \pm$ 4.8 years, in proportions representative of Busan's population, $39.4 \%$ of whom are male, $60.6 \%$ of whom are female. Six trained professionals from a research company, five women and one man, who were carefully trained in extensive interviewing practicum, collected questionnaire data from respondents face-to-face. Respondents were apprised of the purpose of the research, and the content of the survey was fully explained to each participant before receiving written informed consent.

The purpose of the research and the content of the survey's questionnaire were fully explained to each participant before they gave written informed consent. This study was approved by the Institutional Review Board by the Waseda University.

\section{Measures}

\section{A. Health-related quality of life (HRQOL)}

The Korean version of the medical outcomes study (MOS) short form 36-item health survey (SF-36) was administered to assess the HRQOL. The SF-36 
questionnaire has 36 questions that are scored to measure eight domains of HRQL pertaining to both physical and mental aspects. The SF-36 (36 items) consists of eight dimensions: physical functioning (PF: 10 items), general health (GH: 5 items), mental health (MH: 5 items), bodily pain (BP: 2 items), role-physical (RP: 4 items), role-emotional (RE: 3 items), social functioning (SF: 2 items) and vitality (VT: 4 items). The response scores for each dimension are added and the total is converted to a score between 0-100, with higher scores indicating higher levels of HRQOL $[5,18]$. The SF-36 has been used in numerous studies with older adults and has demonstrated high reliability (Chronbach's $\alpha, 0.72$ to 0.94 ) [19,20], construct validity [19] and convergent validity [21]. The reliability of the Korean version of the SF-36 by an alternate-forms method was adequate (Chronbach's $\alpha, 0.71$ to 0.89 ). Also, the Korean version of the SF-36 meets the standard criteria for content and the construct and criterion validity (Chronbach's $\alpha, 0.92$ to 0.93 ) [22]. This study uses it with permission of authors.

\section{B. Demographic and health-related characteristics}

Demographic variables were obtained by questionnaire. Variables comprised gender, age, family status, marital status, education level, and monthly income [23]. There were three age demographics: 65-69, 70-74, and 75 and older [23]. Educational level was also divided in three: unschooled, attended elementary school, and attended middle school or higher [23]. Family status was classified as living alone, living alone with a spouse, and living with other family or relatives; individuals living alone tend to report poor HRQOL $[24,25]$. Respondents were posed with a yes-or-no question used by the Insurance Welfare Family Department to determine their state of physical health: "Do you have any illness that prolongs over three months?" [23]. Height and weight were used to calculate body mass index (BMI), which in turn was divided into the standard three classifications proposed by the World Health Organization: underweight (less than 18.5), normal weight (18.5 to 24.9), and overweight or obese (25.0 or more) [26]. Previous research had also yielded data on how the presence of illness influences the 8-scale health of the SF-36 [27,28], BMI [29], and physical activity [30,31], which were used in the questionnaire.

We estimated amounts of physical activity using the Korean version of the international physical activity questionnaire short version (IPAQ-SV) [32]. IPAQ-SV is a self-reporting survey for estimating weekly amounts of physical activity [33]. The reliability and propriety of the
IPAQ-SV Korean version at measuring high-intensity physical activity, moderate-intensity physical activity, and walking has been verified by a previous study [34]. For the purposes of this study, these physical activity levels were divided into two categories, less than 1500 MET-min/week and more than 1500 METminute/week.

\section{Statistical Analysis}

Analysis object of present research was initially 304 people in total, in which the user of the senior centers were 154 and non-users were 150 . In the 150 non-users 13 people answered the questionnaire on the use of senior centers. Therefore the data of 291 people except the 13 was used to the analysis (male $28.9 \%$, female $71.1 \%$, average age $70.8 \pm 4.3$ years). A chi-squared test was utilized to compare differences in demographic variables among the user and non-users. Additionally, ttests and one-way analysis of variance (ANOVA) were conducted to determine the differences in the SF-36 measures among each demographic and health-related variable. Multivariate analysis of covariance (MANCOVA) was conducted using demographic factors (gender, education level, family status and monthly income) and health-related factors (physical activities and present illness) as covariates, the score of 8-domain scale in SF-36 as a dependent variable, and two groups classified by the usage situation of senior center as an independent variable. The alpha level was set at 0.05. Statistical analysis was performed using SPSS version 18.0 (SPSS Inc., Chicago, IL, USA).

\section{RESULTS}

\section{Basic Characteristics of Respondents}

The average age and standard deviation of the "users" of senior centers were $71.2 \pm 3.7$ years, while for "nonusers" they were $70.3 \pm 4.8$ years. The number of users living with a spouse was 70 out of 154 , or $55.6 \%$. Approximately $83.6 \%$ of users have a monthly income less than one million won. $66.9 \%$ of them, given their BMI, were normal weight. $71.4 \%$ of them performed 1500 METs or more of physical activity weekly. $74.0 \%$ of them had no present illness.

Comparisons between users and non-users revealed that users tended to be older, have lower incomes, and live with their spouses or others. The users also were 
more likely to fall into the normal BMI range, at 18.5$24.9\left(\mathrm{~kg} / \mathrm{m}^{2}\right)$ and tended to perform at least $1500 \mathrm{MET}$ minute of physical activity weekly (Table 1).

\section{Relationship of Demographic Character- istics and Health-Related Characteristics on HRQOL}

The result of t-test and ANOVA in the 8-domain scale in SF-36, demographic and health-related has showed that there were significant differences in gender, education, family status, monthly income, physical activity and present illness. As for gender, female showed higher score than male in subscale of SF-36, physical functioning, bodily pain, general health, vitality, social functioning and role-emotional. As for education, those with higher educational background showed higher scores in all subscale of SF-36 compared with lower educational background. Moreover, the respondent's family status spouses or family showed higher numerical value compared with the respondents living alone. As for physical activity, 1500-minute/week and more in the 8-domain scale except for bodily pain and role-emotional showed higher numerical value compared with the people who performed under 1500minute/week in physical activity. As for present illness, in all subscale, who answered "No" showed higher numerical value compared with the "Yes" (Table 2).

Comparison of differences between demographic and health-related aspects and each domain scale relevant to the SF-36 domain scale was made using t-test and ANOVA. Statistical significance was observed among senior center users and non-users regarding age, education, present illness, physical activities, and family status. For senior center users and gender, the female showed higher values in the domain scale SF-36 VT than that of the male. The SF-36 domain scale BP for senior center users and age were lowest in the age group of 75 or older, and showed higher values in the age group from 65 to 69 than age group 70 to 74 . For senior center users and education, the SF-36 domain scale PF showed the lowest in the group of not school, and are higher in the group of middle school or more compared with the group of elementary school. The SF-36 domain scale $\mathrm{GH}$ for senior center users and present illness gave higher values in respondents with illness than in respondents without illness. All domain scales for senior center users and gender were higher in male than in female. The SF-36 domain scales PF and RP for senior center non-users and age showed the lowest in the age
Table 1. Demographic characteristics of participants

\begin{tabular}{|c|c|c|c|}
\hline & \multicolumn{2}{|c|}{ Participants } & \multirow{2}{*}{$\chi^{2}$} \\
\hline & $\begin{array}{c}\text { Use } \\
\text { senior } \\
\text { center }\end{array}$ & $\begin{array}{l}\text { Not use } \\
\text { senior } \\
\text { center }\end{array}$ & \\
\hline \multicolumn{3}{|l|}{ Gender } & $14.04^{+}$ \\
\hline Male & $29(19.3)$ & $54(39.4)$ & \\
\hline Female & $121(80.7)$ & $83(60.6)$ & \\
\hline \multicolumn{3}{|l|}{ Age (y) } & $24.99^{+}$ \\
\hline $65-69$ & $49(32.5)$ & $78(56.9)$ & \\
\hline $70-74$ & $73(48.3)$ & $29(21.2)$ & \\
\hline $75+$ & $29(19.2)$ & $30(20.9)$ & \\
\hline \multicolumn{3}{|l|}{ Education } & 5.04 \\
\hline Middle school over & $55(42.3)$ & $57(41.6)$ & \\
\hline Elementary school & $66(50.8)$ & $59(43.1)$ & \\
\hline Not school & $9(6.9)$ & $21(15.3)$ & \\
\hline \multicolumn{3}{|l|}{ Family status } & $114.38^{+}$ \\
\hline Living alone & $35(27.8)$ & $46(33.6)$ & \\
\hline Spouse olny & $70(55.6)$ & $0(0.0)$ & \\
\hline Other famaily or relative & $21(15.7)$ & $91(66.4)$ & \\
\hline \multicolumn{3}{|l|}{ Monthly income (KRW) } & $18.07^{+}$ \\
\hline$<999999$ & $97(83.6)$ & $81(59.1)$ & \\
\hline$\geq 1000000$ & $19(16.4)$ & $56(40.9)$ & \\
\hline \multicolumn{3}{|l|}{$\operatorname{BMl}\left(\mathrm{kg} / \mathrm{m}^{2}\right)$} & 5.54 \\
\hline$<18.4$ & $3(1.9)$ & $6(4.4)$ & \\
\hline $18.5-24.9$ & $103(66.9)$ & $74(54.0)$ & \\
\hline$\geq 25.0$ & $45(31.2)$ & $57(41.6)$ & \\
\hline \multicolumn{3}{|c|}{ Physical activity (MET-min/wk) } & $53.55^{\dagger}$ \\
\hline$<1500$ & $44(28.6)$ & $98(71.5)$ & \\
\hline$\geq 1500$ & $110(71.4)$ & $39(28.5)$ & \\
\hline \multicolumn{3}{|l|}{ Present illness } & 1.76 \\
\hline Yes & $32(26.0)$ & $46(33.6)$ & \\
\hline No & $91(74.0)$ & $91(66.4)$ & \\
\hline
\end{tabular}

If there is missing value in each item the figure may not reach $\mathrm{N}$, KRW: Korean won.

${ }^{*} p<0.05,{ }^{+} p<0.001$.

group 75 or older, and showed higher values in the age group from 65 to 69 than age group 70 to 74 . For senior center non-users and education, the SF-36 domain scales $\mathrm{RP}, \mathrm{GH}, \mathrm{VT}, \mathrm{RE}$, and MH were low in the group of no education, and were higher in the group of middle school or more compared with the group of elementary school. All the domain scales of SF-36 for senior center non-users and presence of persons living with showed higher values. For BMI of non-users, BP was the lowest in $18.4\left(\mathrm{~kg} / \mathrm{m}^{2}\right)$, and higher in $18.5-24.9\left(\mathrm{~kg} / \mathrm{m}^{2}\right)$ than in 25.0 or more $\left(\mathrm{kg} / \mathrm{m}^{2}\right)$. For physical activity levels of nonusers, PF, RP, RE, VT, SF, RE, and MH of SF-36 were higher in the population with low physical activity levels than in the population with higher physical activity levels. All the domain scales of SF-36 for non-users and present illness showed higher values in the population with illness than the population without illness.

III. Relationship of the State of Senior Center on HRQOL 
Table 2. Mean SF-36 scores for study participants: univariate analysis by demographic characteristics and health-related characteristics

\begin{tabular}{|c|c|c|c|c|c|c|c|c|}
\hline & $\mathrm{PF}$ & $\mathrm{RP}$ & $\mathrm{BP}$ & $\mathrm{GH}$ & VT & SF & RE & $\mathrm{MH}$ \\
\hline \multicolumn{9}{|l|}{ Gender } \\
\hline Male & $84.4 \pm 11.4$ & $91.4 \pm 14.6$ & $85.4 \pm 18.9$ & $67.3 \pm 16.9$ & $68.6 \pm 13.6$ & $93.6 \pm 12.9$ & $96.2 \pm 8.1$ & $80.2 \pm 10.0$ \\
\hline Female & $70.8 \pm 20.8$ & $91.4 \pm 23.9$ & $66.7 \pm 27.2$ & $51.4 \pm 23.3$ & $57.7 \pm 19.3$ & $81.5 \pm 23.0$ & $83.3 \pm 18.3$ & $69.4 \pm 15.8$ \\
\hline$p$-value & $<0.001$ & $<0.001$ & $<0.001$ & $<0.001$ & $<0.001$ & $<0.001$ & $<0.001$ & $<0.001$ \\
\hline \multicolumn{9}{|l|}{ Age (y) } \\
\hline $65-69$ & $77.6 \pm 17.0$ & $84.7 \pm 18.2$ & $73.3 \pm 24.4$ & $59.3 \pm 22.2$ & $62.4 \pm 17.9$ & $85.9 \pm 19.7$ & $89.8 \pm 13.9$ & $73.3 \pm 15.4$ \\
\hline $70-74$ & $72.0 \pm 21.9$ & $78.6 \pm 26.9$ & $73.3 \pm 29.6$ & $52.9 \pm 23.1$ & $61.2 \pm 19.4$ & $84.0 \pm 23.9$ & $84.8 \pm 21.3$ & $72.3 \pm 15.6$ \\
\hline $75+$ & $70.4 \pm 21.3$ & $77.7 \pm 27.4$ & $67.4 \pm 27.0$ & $52.0 \pm 23.1$ & $56.1 \pm 18.2$ & $84.3 \pm 21.8$ & $83.1 \pm 17.3$ & $71.1 \pm 14.0$ \\
\hline$p$-value & 0.061 & 0.137 & 0.489 & 0.122 & 0.204 & 0.848 & 0.064 & 0.727 \\
\hline \multicolumn{9}{|l|}{ Education } \\
\hline Middle school & $82.2 \pm 14.0$ & $86.2 \pm 18.9$ & $80.5 \pm 22.9$ & $64.2 \pm 18.3$ & $67.0 \pm 14.9$ & $90.2 \pm 16.2$ & $91.0 \pm 14.7$ & $78.0 \pm 11.5$ \\
\hline Elementary school & $69.4 \pm 21.8$ & $78.6 \pm 24.7$ & $64.7 \pm 27.1$ & $51.8 \pm 24.5$ & $57.0 \pm 20.3$ & $80.3 \pm 25.1$ & $85.0 \pm 18.1$ & $69.2 \pm 17.1$ \\
\hline Not school & $64.3 \pm 20.2$ & $73.9 \pm 24.3$ & $64.5 \pm 28.1$ & $39.0 \pm 19.6$ & $50.3 \pm 17.0$ & $80.7 \pm 21.1$ & $79.1 \pm 18.3$ & $62.9 \pm 13.0$ \\
\hline $\mathrm{p}$-value & $<0.001$ & 0.017 & $<0.001$ & $<0.001$ & $<0.001$ & 0.006 & 0.003 & $<0.001$ \\
\hline \multicolumn{9}{|l|}{ Family status } \\
\hline Living alone & $66.6 \pm 23.6$ & $73.9 \pm 25.9$ & $63.0 \pm 29.3$ & $46.0 \pm 17.6$ & $53.1 \pm 21.1$ & $77.5 \pm 25.3$ & $81.6 \pm 17.3$ & $63.8 \pm 17.7$ \\
\hline Spouse only & $80.8 \pm 13.8$ & $84.8 \pm 13.9$ & $75.0 \pm 25.7$ & $60.0 \pm 17.6$ & $66.4 \pm 12.6$ & $87.8 \pm 17.5$ & $88.1 \pm 13.2$ & $74.1 \pm 11.2$ \\
\hline Other famaily or relative & $77.6 \pm 17.1$ & $85.1 \pm 21.7$ & $76.6 \pm 23.6$ & $60.6 \pm 21.1$ & $63.5 \pm 17.2$ & $88.5 \pm 18.8$ & $90.0 \pm 17.4$ & $77.2 \pm 12.4$ \\
\hline$p$-value & 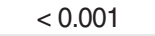 & 0006 & 0006 & O 001 & $<0001$ & 0.005 & 0.010 & $<0.001$ \\
\hline \multicolumn{9}{|l|}{ Monthly income (KRW) } \\
\hline$<999999$ & $74.0 \pm 20.2$ & $80.4 \pm 23.4$ & $69.5 \pm 27.6$ & $53.5 \pm 22.3$ & $58.6 \pm 18.9$ & $84.0 \pm 22.3$ & $84.7 \pm 17.9$ & $69.9 \pm 15.4$ \\
\hline$\geq 1000000$ & $76.7 \pm 17.9$ & $84.2 \pm 20.1$ & $77.8 \pm 22.9$ & $61.6 \pm 22.9$ & $65.7 \pm 16.7$ & $87.2 \pm 18.8$ & $92.2 \pm 13.8$ & $78.3 \pm 13.0$ \\
\hline$p$-value & 0.357 & 0.275 & 0.042 & 0.022 & 0.013 & 0.325 & 0.005 & $<0.001$ \\
\hline \multicolumn{9}{|l|}{ BMI $\left(\mathrm{kg} / \mathrm{m}^{2}\right)$} \\
\hline$<24.9$ & $75.7 \pm 18.3$ & $83.5 \pm 19.4$ & $73.5 \pm 25.1$ & $58.0 \pm 22.6$ & $62.0 \pm 16.9$ & $85.3 \pm 21.3$ & $87.3 \pm 16.5$ & $73.5 \pm 14.0$ \\
\hline$\geq 25.0$ & $73.5 \pm 21.4$ & $78.7 \pm 26.4$ & $70.1 \pm 28.4$ & $53.1 \pm 22.8$ & $59.1 \pm 20.7$ & $84.6 \pm 21.2$ & $86.9 \pm 17.9$ & $71.2 \pm 16.9$ \\
\hline $\mathrm{p}$-value & 0.443 & 0.146 & 0.395 & 0.149 & 0.289 & 0.807 & 0.881 & 0.297 \\
\hline \multicolumn{9}{|l|}{ Physical activity (min/wk) } \\
\hline$<1500$ & $64.5 \pm 26.9$ & $72.9 \pm 30.3$ & $66.4 \pm 30.4$ & $49.5 \pm 27.0$ & $53.7 \pm 23.0$ & $76.8 \pm 26.3$ & $83.5 \pm 21.3$ & $66.5 \pm 18.8$ \\
\hline$\geq 1500$ & $81.2 \pm 13.0$ & $87.2 \pm 14.7$ & $75.3 \pm 23.7$ & $61.7 \pm 19.4$ & $66.2 \pm 14.8$ & $89.2 \pm 17.7$ & $89.5 \pm 14.3$ & $75.7 \pm 12.4$ \\
\hline$p$-value & $<0.001$ & $<0.001$ & 0.063 & 0.003 & $<0.001$ & 0.001 & 0.051 & 0.001 \\
\hline \multicolumn{9}{|l|}{ Present illness } \\
\hline Yes & $64.2 \pm 23.2$ & $71.4 \pm 28.8$ & $58.1 \pm 27.2$ & $40.7 \pm 23.2$ & $52.1 \pm 21.5$ & $74.1 \pm 25.6$ & $80.8 \pm 20.2$ & $65.0 \pm 18.1$ \\
\hline No & $79.7 \pm 15.5$ & $86.3 \pm 17.1$ & $78.5 \pm 23.2$ & $63.1 \pm 18.9$ & $64.9 \pm 15.4$ & $90.0 \pm 16.9$ & $90.0 \pm 14.6$ & $76.0 \pm 12.3$ \\
\hline$p$-value & $<0.001$ & $<0.001$ & $<0.001$ & $<0.001$ & $<0.001$ & $<0.001$ & $<0.001$ & $<0.001$ \\
\hline
\end{tabular}

PF: physical functioning, RP: role-physical, BP: bodily pain, GH: general health,VT: vitality, SF: social functioning, RE: role-emotional, MH: mental health, $\mathrm{HRQOL}$ : health related quality of life scale.

These results are based on comparisons between certain demographic variables (gender, education, family status, and monthly income) [23-25] and health-related variables (physical activities and present illness that affect SF-36 scores) [26-28]. Physically, it was found that users of senior centers had significantly higher physical functionality and role-physical $(\mathrm{F}=4.87$, $\mathrm{p}=0.027$ and $\mathrm{F}=7.02, \mathrm{p}=0.009$, respectively), and mentally, too, the users had significantly higher levels of vitality at $\mathrm{F}=7.48, \mathrm{p}=0.007$ (Table 3 ).

\section{DISCUSSION}

This study aimed at identifying the effects of using senior centers on senior citizens' HRQOL while taking into account aspects both physical and mental. After adjusting for demographic and health-related factors, the users of senior centers, more than the non-users, showed higher scores in physical function, role physical, and vitality. Based on these results, it seems safe to assume that using the centers benefits senior citizens in terms of HRQOL not only physically but mentally as well.

In terms of physical wellbeing, this study confirmed previous research reporting a positive correlation. Senior center users score higher in physical functionality and role physical. Studies conducted in countries other than in Korea have shown, for instance, that step-counts [35], muscular strength, and balance [36] are higher among users of senior centers that offer resistance training and exercise. In general, research using SF-36 has shown that people who live active lives score higher for physical wellness. [30]. This study supports those findings.

Furthermore, this study revealed that senior center users enjoy higher mental wellness, measured in terms 
Table 3. Adjusted HRQOL measures in respondents among use of senior centers

\begin{tabular}{|c|c|c|c|c|}
\hline & \multicolumn{4}{|c|}{ Senior center } \\
\hline & $\begin{array}{l}\text { Use senior } \\
\text { center } \\
(n=154)\end{array}$ & $\begin{array}{l}\text { Non-use } \\
\text { senior center } \\
\quad(n=137)\end{array}$ & $F$ & $p$ \\
\hline Physical functioning & $80.82 \pm 13.68$ & $74.24 \pm 21.68$ & 4.97 & 0.027 \\
\hline Role physical & $87.39 \pm 13.68$ & $80.90 \pm 24.22$ & 7.02 & 0.009 \\
\hline Bodily pain & $72.76 \pm 26.10$ & $72.18 \pm 26.00$ & 0.20 & 0.649 \\
\hline General health & $60.85 \pm 17.57$ & $57.00 \pm 24.79$ & 2.99 & 0.086 \\
\hline Vitality & $67.76 \pm 12.14$ & $59.94 \pm 20.57$ & 7.48 & 0.007 \\
\hline Social functioning & $87.72 \pm 17.92$ & $84.78 \pm 22.75$ & 1.39 & 0.240 \\
\hline Role emotional & $85.76 \pm 15.18$ & $89.22 \pm 17.49$ & 0.33 & 0.565 \\
\hline Mental health & $74.00 \pm 10.42$ & $72.77 \pm 17.16$ & 1.29 & 0.256 \\
\hline \multicolumn{5}{|c|}{$\begin{array}{l}\text { HRQOL : health related quality of life scale. } \\
\text { Comparison in multidimensional scales SF-36 (short form-36) among } \\
\text { use of senior center with covariate of gender, monthly income, } \\
\text { education, live with, physical activity, present illness. }\end{array}$} \\
\hline
\end{tabular}

of HRQOL as vitality, than non-users. Previous studies conducted in countries other than in Korea have shown that the use of senior centers can improve psychological wellbeing, help alleviate depression [37], foster friendships and social interaction [38], and reduce stress levels [39]. Indeed, senior citizens report that active participation in these social activities improves their psychological QOL because the activities add pleasure to their lives. The results of this study confirm as much, that there is a positive correlation between utilizing senior centers and mental HRQOL.

Although senior center users scored higher than nonusers in the previously mentioned categories, there was no significant statistical difference found for certain physical aspects such as BP or GH. Perhaps this was because a particularly healthy group of senior citizens took part in this study. The percentage of chronic disease morbidity among users was $26.0 \%$ and among non-users was $33.6 \%$. These percentages were lower than those reported by the Insurance Welfare Family Department [23], and thus healthier than average subjects may have affected these results. Regardless, the overall percentage of chronic disease morbidity in Korea is high, and subjective recognition of healthiness remains low [23]. Chronic illness prevention and health promotion programs at senior centers must be modified, perhaps to include a nurse or specialist or to involve local public healthcare centers, to serve the diverse needs specific to seniors.

Some miscellaneous differences between users and non-users should also be noted. Most demographic variables coincide with the results of earlier studies on HRQOL. Users showed higher over SF-36 scores than non-users. Old age is indicative of poorer physical health, yet better mental health [24]. Participants living alone reported poor HRQOL [25]. Higher educational attainment was associated with better HRQOL [24]. Being underweight or obese leads to considerably poorer HRQOL [29]. The HRQOL scores were higher in individuals with lower physical activity levels than in those with higher physical activity levels [31]. Moreover, no relationship was found between the subscales of mental wellbeing, for instance, mental health, role emotional, and social functioning. Further research is necessary to determine the independent impact on HRQOL of particular cultural and educational programs offered by senior centers. And overall, we conclude that there must be more discussion of business models and institutional organizations that successfully improve, both mentally and physically, the HRQOL and longterm health care needs of the growing population of our senior citizens.

Lastly, here are some limitations to this study. First, the findings were derived from a cross-sectional population. Therefore, the causation between senior center utilization and HRQOL may not be strictly inferred. An intervention study would be necessary for confirming a causal relationship. Second, this study relies heavily on physical aspects like present illness and BMI in determining overall HRQOL. Mental aspects in and of themselves were not isolated. Evidence of depression, which is increasingly common in elderly populations, should be given more weight and attention. Third, some social element, as recognized in the SF-36, seems relevant to gaining a complete picture of HRQOL. How much social support are these senior citizens receiving and how does it affect their social functionality? Fourth, this study used data collected through face-to-face interviews not self-reporting. However skilled the interviewers, differences may arise because of the format. Moreover, older people tend to over- and under-report depending on the time and place of the interview. QOL may thus contain over-reporting, a tendency more frequent to face-to-face interviews. Response time also seems to influence the respondents' feelings on quality of life issues. To minimize the effects of these limitations, in-depth interviews may be more effective for research targeted at senior centers.

The present study showed that the users of the senior centers have higher physical functioning, role-physical and vitality compared with the non-users. These findings suggest that although the results are unable to give specific causal relationships, using a senior center may lead to some health related benefits for quality of life. This study demonstrated that the use of senior centers is related to the health-related QOL thus the use of senior 
centers will affect the health of older adults. To promote the use of senior centers in future, it is necessary to identify mental, social, and environmental aspects affecting the behavior of non-users. Therefore, form plans for promoting the uses of senior centers are needed. Moreover, formulating strategies promoting the participation of non-profit group are necessary.

\section{ACKNOWLEDGEMENTS}

The authors wish to thank Professor SKP and his students (University of Dong-A, Korea) for assisting with data preparation. This study was supported by grants from the Waseda University Global COE Program "Sports Science for the Promotion of Active Life" None of the authors had any conflict of interest regarding any aspect of this research.

\section{CONFLICT OF INTEREST}

The authors have no conflicts of interest with the material presented in this paper.

\section{REFERENCES}

1. Feeny DH, Torrance GW. Incorporating utility-based quality-of-life assessment measures in clinical trials. Two examples. Med Care 1989; 27(3 Suppl): S190-S204.

2. Guyatt GH. A taxonomy of health status instruments. $J$ Rheumatol 1995; 22(6): 1188-1190.

3. Bowling A. The concept of quality of life in relation to health. Med Secoli 1995; 7(3): 633-645.

4. Idler EL, Benyamini Y. Self-rated health and mortality: a review of twenty-seven community studies. J Health Soc Behav 1997; 38(1): 21-37.

5. Ware JE Jr, Sherbourne CD. The MOS 36-item short-form health survey (SF-36). I. Conceptual framework and item selection. Med Care 1992; 30(6): 473-483.

6. Mishoe SC, Maclean JR. Assessment of health-related quality of life. Respir Care 2001; 46(11): 1236-1257.

7. Jacobzone S. Ageing and care for frail elderly persons: an overview of international perspectives. Paris: Organisation for Economic Cooperation and Development; 1999.

8. Kwon JH, Lee JS, Han EJ, Park JY. A study on policy development to prevent the functional decline in older people. Seoul: National Health Insurance Corporation; 2009. p. 29-32. (Korean)

9. Park JY, Kwon JH, Lee JS, Kang IO, Lee YH, Kim DH. The object people for long-term care insurance for older adults and the research of the service enlarge measure. Seoul: National Health Insurance Corporation; 2008. p. 2528. (Korean)

10. Fitzpatrick TR, Spiro A III, Kressin NR, Greene E, Bosse R. Leisure activities, stress and health among bereaved and non-bereaved elderly men: the normative aging study. Omega (Westport) 2001; 43(3): 217-245.

11 . Krout JA. Senior center programming and frailty among older persons. J Gerontol Soc Work 1997; 26(3/4): 19-34.

12. Choi EJ, Seo MK, Sun WD, Kim DJ, No JM, et al. Study on developing elderly health promotion model through utilizing senior welfare associated facilities. Seoul; Korea Institute for Health and Social Affairs; 2007. (Korean)

13. Ralston PA. Senior center utilization by black elderly adults: social, attitudinal and knowledge correlates. $J$ Gerontol 1984; 39(2): 224-229.

14. Schneider MJ, Chapman DD, Voth DE. Senior center participation: a two-stage approach to impact evaluation. Gerontologist 1985; 25(2): 194-200.

15. Krout JA, Culter SJ, Coward RT. Correlates of senior center participation: a national analysis. Gerontologist 1990; 30(1): 72-79.

16. Gelfand DE, Bechill W, Chester RL. Core programs and services at senior centers. J Gerontol Soc Work 1991; 17(1/2): 145-161.

17. Strain LA. Senior centers: who participates? Can J Aging 2001; 20(4): 471-491.

18. Ware JE Jr, Kosinski M, Bayliss MS, McHorney CA, Rogers WH, Raczek A. Comparison of methods for the scoring and statistical analysis of SF-36 health profile and summary measures: summary of results from the Medical Outcomes Study. Med Care 1995; 33(4 Suppl): AS264AS279.

19. Lyons RA, Perry HM, Littlepage BN. Evidence for the validity of the Short-form 36 Questionnaire (SF-36) in an elderly population. Age Ageing 1994; 23(3): 182-184.

20. Pit SW, Schurink J, Nair BR, Byles J, Heller RF. Use of the Short-form-36 health survey to assess quality of life among Australian elderly. Australas J Ageing 1996; 15(3): 132-135.

21. Andresen EM, Gravitt GW, Aydelotte ME, Podgorski CA. Limitations of the SF-36 in a sample of nursing home residents. Age Ageing 1999; 28(6): 562-566.

22. Han CW, Lee EJ, Iwaya T, Kataoka H, Kohzuki M. Development of the Korean version of Short-form 36-Item Health Survey: health related QOL of healthy elderly people and elderly patients in Korea. Tohoku J Exp Med 2004; 203(3): 189-194.

23. Korea Institute for Health and Social Affairs. Actual condition survey on older adults: Korean older adults actual life condition, and a survey desire. Seoul; Korea Institute for Health and Social Affairs; 2009 (Korean)

24. Lam CL, Lauder IJ. The impact of chronic diseases on the health-related quality of life (HRQOL) of Chinese patients in primary care. Fam Pract 2000; 17(2): 159-166. 
25. Lubetkin EI, Jia H, Gold MR. Construct validity of the EQ-5D in low-income Chinese American primary care patients. Qual Life Res 2004; 13(8): 1459-1468.

26. WHO, Expert Committee on Physical Status; The Use and Interpretation of Anthropometry. Physical status: the use and interpretation of anthropometry: report of a WHO Expert Committee. Geneva: World Health Organization; 1995. p. 1-452.

27. Lam CL, Fong DY, Lauder IJ, Lam TP. The effect of health-related quality of life (HRQOL) on health service utilization of a Chinese population. Soc Sci Med 2002; 55(9): 1635-1646.

28. Wang HM, Beyer M, Gensichen J, Gerlach FM. Healthrelated quality of life among general practice patients with differing chronic diseases in Germany: cross sectional survey. BMC Public Health 2008; 8: 246.

29. Yan LL, Daviglus ML, Liu K, Pirzada A, Garside DB, Schiffer L, et al. BMI and health-related quality of life in adults 65 years and older. Obes Res 2004; 12(1): 69-76.

30. Acree LS, Longfors J, Fjeldstad AS, Fjeldstad C, Schank $\mathrm{B}$, Nickel KJ, et al. Physical activity is related to quality of life in older adults. Health Qual Life Outcomes 2006; 4: 37.

31. Shibata A, Oka K, Nakamura Y, Muraoka I. Prevalence and demographic correlates of meeting physical activity recommendation among Japanese adults. $J$ Phys Act Health 2009; 6(1): 24-32.

32. Kim BS. Korean version of international physical activity questionnaire (IPAQ) short form. J Korean Acad Fam Med 2006; 27(4 Suppl): S348-S357. (Korean)
33. Craig CL, Marshall AL, Sjöström M, Bauman AE, Booth ML, Ainsworth BE, et al. International physical activity questionnaire: 12-country reliability and validity. Med Sci Sports Exerc 2003; 35(8): 1381-1395.

34. Oh JY, Yang YJ, Kim BS, Kang JH. Validity and reliability of Korean version of international physical activity questionnaire (IPAQ) short form. J Korean Acad Fam Med 2007; 28(7): 532-541. (Korean)

35. Sarkisian CA, Prohaska TR, Davis C, Weiner B. Pilot test of an attribution retraining intervention to raise walking levels in sedentary older adults. J Am Geriatr Soc 2007; 55(11): 1842-1846.

36. Manini T, Marko M, VanAmam T, Cook S, Fernhall B, Burke J, et al. Efficacy of resistance and task-specific exercise in older adults who modify tasks of everyday life. J Gerontol A Biol Sci Med Sci 2007; 62(6): 616-623.

37. Choi NG, McDougall GJ. Comparison of depressive symptoms between homebound older adults and ambulatory older adults. Aging Ment Health 2007; 11(3): 310-322.

38. Aday RH, Kehoe GC, Farney LA. Impact of senior center friendships on aging women who live alone. $J$ Women Aging 2006; 18(1): 57-73.

39. Farone DW, Fitzpatrick TR, Tran TV. Use of senior centers as a moderator of stress related distress among Latino elders. J Gerontol Soc Work 2005; 46(1): 65-83. 